\title{
Impact of a Non-Phthalate Based Internal Donor on the Polymerization Behaviour of a Novel Ziegler - Natta Catalyst
}

\author{
Jingbo Wang, ${ }^{1}$ Markus Gahleitner, ${ }^{1}$ Peter Denifl, ${ }^{1}$ Pauli Leskinen, ${ }^{2}$ Johanna Lilja ${ }^{2}$ \\ ${ }^{1}$ Borealis Polyolefine GmbH, Innovation Headquarters \\ St. Peterstr. 25, 4021 Linz, Austria \\ jingbo.wang@borealisgroup.com; markus.gahleitner@borealisgroup.com; peter.denifl@borealisgroup.com; \\ ${ }^{2}$ Borealis Polymers Oy, \\ Muovintie 19, FI-06850 Kulloo, Porvoo, Finland \\ pauli.leskinen@borealisgroup.com; johanna.lilja@borealisgroup.com
}

\section{Extended Abstract}

With a global share of nearly $20 \%$ in the thermoplastics market and an annual growth rate of more than $4 \%$, polypropylene plays a special role in the group of so-called "commodity polymers". One key reason for this success is the flexibility in terms of composition and property design. The major part of the industrial production of polypropylene is based on $\mathrm{MgCl}_{2}$-supported Ziegler-Natta catalysts. [1] Starting from the third generation Ziegler-Natta catalysts, an internal electron donor has been widely used to boost the performance of the catalyst; it does not only influence the activity, but also controls the molecular structure, like the isotacticity and comonomer insertion in case a second monomer is applied. [2-3] Actually, the electron donor is one of key factors to classify the generation of Ziegler-Natta catalysts.

In the current study, the impact of a non-phthalate based internal donor on the polymerization behaviour of a novel Ziegler-Natta catalyst from an emulsion process was evaluated. [4-5] Changing the internal donor from phthalate to nonphthalate compound significantly changes the $\mathrm{H}_{2}$ response of the catalyst. High melt flow rate products are easily achieved with the new catalyst, which is desired in many applications. Isotacticity of the homopolymer, evaluated with ${ }^{13} \mathrm{C}$ NMR, increases significantly with this new catalyst, therefore the properties of the products are improved, e.g. the stiffness. Moreover, the new internal donor can supress the production of oligomers, reducing the amount of volatiles of the finished products. In the end, the benefits of the new catalyst in certain application areas, e.g. thin wall packaging, are demonstrated. The new donor changes the comonomer insertion, therefore the long term performance is improved significantly. [6]

\section{References}

[1] A. Addeo, Polypropylene Handbook. Cambridge, Hanser, 2005.

[2] T. Taniike and M. Terano, "The Use of Donors to Increase the Isotacticity of Polypropylene," in Polyolefins: 50 years after Ziegler and Natta, W. Kaminsky, Ed. Springer Nature Switzerland AG, 2018, pp. 81 - 97.

[3] T. Vestberg, M. Parkinson, I. Fonseca C. Wilén, "Poly(propylene-co-ethylene) produced with a conventional and a self-supported ziegler-natta catalyst: Effect of ethylene and hydrogen concentration on activity and polymer structure," J. Appl. Polym. Sci., Vol. 124, no. 6, pp. 4889 - 4896.

[4] L. Timo, J. Lilja, P. Denifl, M. Gahleitner, T. Horill, J. Wang, "Low emission propylene homopolymer with high melt flow," EP3071606, Nov. 22, 2013.

[5] J. Wang, J. Lilja, T. Horill, M. Gahleitner, P. Denifl, L. Timo, "Low emission propylene homopolymer," EP3071607, Nov. 22, 2013.

[6] J. Wang, M. Gahleitner, J. Braun, D. Tranchida, "Comonomer distribution effect on the ageing behavior of ethylenepropylene random copolymers," in AIP Conference Proceedings, Ischia, Italy, 2018, vol. 1981, 020049 